\title{
Enhanced Serologically Based Detection of Liberibacters Associated with Citrus Huanglongbing
}

\author{
Fang Ding, ${ }^{1,2,3}$ Shu-ang Peng, ${ }^{2}$ and John S. Hartung, ${ }^{3, \dagger}$ \\ ${ }^{1}$ Hubei Key Laboratory of Plant Pathology, College of Plant Science and Technology, Huazhong Agricultural University, \\ Wuhan, 430070 P.R. China \\ ${ }^{2}$ Key Laboratory of Horticultural Plant Biology (Huazhong Agricultural University), Ministry of Education, Wuhan, 430070 P.R. \\ China \\ ${ }^{3}$ United States Department of Agriculture, Agricultural Research Service Molecular Plant Pathology Laboratory, Beltsville, MD \\ 20705, U.S.A.
}

\begin{abstract}
'Candidatus Liberibacter spp.' are associated with the most devastating disease of citrus Huanglongbing (HLB). In previous work, we established an in situ tissue print method for the detection of ' $\mathrm{Ca}$. L. asiaticus' (CLas) in sweet orange. We optimized the protocol by preincubation of the anti-Omp antibody with $5 \%(\mathrm{w} / \mathrm{v})$ extract of healthy rough lemon. This simple process eliminated cross reactions between citrus and the antibody. The optimized protocol enhanced the application of the polyclonal antibody, and we demonstrate detection of CLas from all parts of the world, including isolates from Japan, Thailand, Vietnam, Pakistan, Saudi Arabia, Brazil, the United States, and a selec-

corresponding outer membrane genes of representative isolates were cloned and sequenced. The coding sequences were highly conserved, and isolates of CLas and CLaf shared 53.8 to $55.9 \%$ identity between species at the amino acid level. The optimized protocol is efficient for recognition of both CLas and CLaf in phloem cells of different citrus tissues regardless of geographic origin of the HLB samples. The method is simple and scales well to match the urgent need for accurate, sensitive, and high-throughput screening of HLB bacteria, and may play an important role especially for plant inspection and quarantine programs.
\end{abstract} tion of strains from China representative of the diversity extant there. The assay also was used to detect four isolates of ' $\mathrm{Ca}$. L. africanus' (CLaf) representative of the diversity present in South Africa. The
Keywords: Candidatus Liberibacter, huanglongbing, serological detection, DTBIA
Huanglongbing (HLB), also known as citrus greening, is a century-old disease (Bové 2006) that threatens the health and development of the citrus industry globally, causing serious economic losses (Gottwald 2010). HLB has been the focus of research by the international citrus community since the discovery of the disease in Florida, U.S.A. (Halbert 2005) and São Paulo, Brazil (ColettaFilho et al. 2004; Teixeira et al. 2005). A phloem-limited gramnegative $\alpha$-proteobacterium is always associated with the disease (Garnier et al. 1984). Three bacteria, 'Candidatus Liberibacter asiaticus' (CLas), ' $\mathrm{Ca}$. L. africanus' (CLaf), and ' $\mathrm{Ca}$. L. americanus' (CLam) are associated with HLB. The liberibacters are distinguished by $16 \mathrm{~S}$ RNA sequence and are found in different geographic regions (Jagoueix et al. 1994; Teixeira et al. 2005). CLam was briefly important in Brazil but has been replaced by CLas (Ayres et al. 2012). CLaf is the only liberibacter in citrus in South Africa and is widespread there (Pietersen et al. 2010). CLas is the only species distributed and prevalent in major citrus growing areas worldwide, and all aspects of the HLB pathosystem make HLB uniquely difficult to

${ }^{\dagger}$ Corresponding author: J. S. Hartung; john.hartung@usda.gov

Funding: This study was funded by the National Key Research \& Development Program of China (2017YFD0202000), USDA ARS project 9018042560-301, USDA NIFA project 6081245001, the National Key Research and Development Program of China (2018YFD0201500), and the National Natural Science Foundation of China (31872077).

The author(s) declare no conflict of interest.

Accepted for publication 31 January 2020.

(C) 2020 The American Phytopathological Society control (Gottwald and McCollum 2017). Liberibacters are typical intracellular pathogens, with significantly reduced genomes (Duan et al. 2009; Lin et al. 2015; Wulff et al. 2014). CLas is transmitted by grafting or by psyllid vectors, primarily by Diaphorina citri Kuwayama worldwide (Capoor et al. 1967; Martinez and Wallace 1967) and also in China by Cacopsylla citrisuga Yang and Li (Cen et al. 2012). CLaf is transmitted by Trioza erytreae Del Guercio in Africa (da Graca 1991). Typical symptoms of HLB begin with yellow shoots that develop into mature leaves with a distinctive blotchy mottle or zinc deficiency. Fruits may be malformed with color inversion. Leaf and fruit drop and shoot dieback are part of a subsequent decline that greatly shortens the productive lifespan of citrus trees (Bové 2006; Halbert 2005; Wang and Trivedi 2013). Liberibacters can infect all citrus species or cultivars (Bové 2006). Detection and identification of plant pathogens are critical for appropriate application of phytosanitary measures (De Boer and Lopez 2012). Although liberibacters are present systemically in infected trees, frequent low concentration and extremely uneven distribution of these bacteria within infected trees create a sampling problem for reliable detection, regardless of the detection method, even for symptomatic tissues $(\mathrm{Li}$ et al. 2009; Tatineni et al. 2008). A variety of methods have been developed for the identification and detection of liberibacters (Arredondo Valdés et al. 2016). These techniques began with biological indexing by graft transmission and imaging the pathogen by transmission electron microscopy (Garnier et al. 1984). DNA-based detection by conventional polymerase chain reaction (PCR) (Hocquellet et al. 1999), quantitative PCR (qPCR) (Li et al. 2006), and loop-mediated isothermal amplification (Okuda et al. 2005) are widely used to detect liberibacters. Several direct tissue blot immunoassays (DTBIAs) have been widely used for the detection and localization of viral and mycoplasma-like pathogens in plants for many 
years (Lin et al. 1990). Due to the fastidious nature of liberibacters, polyclonal antibodies (Pab) raised against whole bacterial cells have not been produced. Monoclonal antibodies, produced with homogenates of infected periwinkle phloem tissues as immunogens, were highly strain specific and reacted only with the homologous HLB strain (Korsten et al. 1993; Villechanoux et al. 1992), which was unsuitable for practical application. In our previous work, we used PCR-based cloning to obtain a portion of an outer membrane protein (Omp; YP_003065185.1) of CLas and used purified Omp protein expressed in vitro as an immunogen to produce anti-Omp Pab in New Zealand white rabbit (Ding et al. 2015, 2016). We demonstrated that the antiserum can specifically recognize CLas in different citrus tissues with DTBIA or immunocapture PCR (Ding et al. 2017). Our previous work used plant material affected by CLas and samples collected in the United States and a limited number of foreign isolates. To determine whether our anti-Omp antiserum can recognize CLas strains from distinct geographic origins, CLas strains collected from Japan, Thailand, Vietnam, Pakistan, Saudi Arabia, China, Brazil, and the United States (Florida, Texas, and California) and four CLaf isolates from South Africa were all tested. Our results demonstrate the detection of both CLas and CLaf in a simple DTBIA in a broad array of samples from citrus. Our DTBIA results were consistent with results of qPCR assays of the same samples for the liberibacters as well as three-dimensional modeling of Omp and an in silico prediction of antigenic determinants.

CLas- and CLaf-infected samples were propagated by bud inoculation of either rough lemon (Citrus jambhiri Lush.) or sweet orange (Citrus sinensis [L.] Osbeck) seedlings propagated on rough lemon rootstocks in Beltsville, Maryland (Ding et al. 2015). Field samples of leaves were collected in China directly from citrus groves in eight provinces (Table 1) and then stored in a $4^{\circ} \mathrm{C}$ refrigerator before use. HLB-affected citrus tissues with the corresponding healthy controls were collected and kept on ice before the DTBIA. For DTBIA with CLas/CLaf-infected lemon samples, protocols were as published (Ding et al. 2015, 2016), except that a blocking step was added to eliminate nonspecific cross reactions between the host and antiOmp antiserum. Five grams of fresh lemon midribs was ground with liquid nitrogen into a fine powder and then transferred to $100 \mathrm{ml}$ of blocking buffer (phosphate-buffered saline with Tween $20+5 \%$ fat free skim milk) to prepare preblocking buffer (PBB). The antiserum was diluted 5,000-fold with PBB and incubated at room temperature for $1 \mathrm{~h}$ before membranes with tissue prints were added and incubated for $1 \mathrm{~h}$ to allow the Pab to bind the Omp protein of CLas or CLaf. The membrane washes, incubation with the secondary antibody, and colorimetric detection of bound primary antibody were as performed previously (Ding et al. 2015, 2016). Individual sections of petioles, midribs, or stems were collected after they were printed on the nitrocellulose membrane, and DNA was extracted with the DNeasy kit (Qiagen, Hilden, Germany). qPCR was performed using the cytochrome oxidase gene as an internal control (Fu et al. 2019b). Cycle quantification $(\mathrm{Cq})$ values greater than 36.9 were considered to be negative for CLas ( $\mathrm{Li}$ et al. 2008).

CLas and CLaf are only found in the phloem of HLB-infected tissues. When rough lemon samples were tested in a preliminary trial, diffuse nonspecific color was observed in the region of vascular tissue, as well as more generally across the tissue prints. To address this, blocking of the antiserum against Omp with different amounts of rough lemon crude extracts (RLCE) was tested. Without blocking, in samples from petioles, midribs, and stems, diffuse purple color was observed in tissue surrounding the phloem, and numerous small dots were seen across whole tissue sections, whether infected by CLas or CLaf or not (Fig. 1). These nonspecific reactions were in addition to the specific signal localized in phloem cells. Similar nonspecific color signals were observed in the healthy petioles and stems. When 5\% RLCE was added to block the antiserum against Omp, purple reactions were specific, and only in the phloem of petioles, midribs, and stems of both CLas- or CLaf-infected tissue prints. No nonspecific reactions were seen from healthy petioles or stems (Fig. 1).

We initially tested CLas isolate B232 from Thailand and CLaf isolate B435 from Letaba, South Africa, propagated on rough lemon

Table 1. Samples collected from different geographical areas and used for both DTBIA and qPCR analysis in this study ${ }^{\mathrm{a}}$

\begin{tabular}{|c|c|c|c|c|c|c|}
\hline $\begin{array}{l}\text { Sample } \\
\text { name }\end{array}$ & Geographical origin & $\begin{array}{c}\text { HLB bacteria } \\
\text { infected }\end{array}$ & Citrus variety tested & $\begin{array}{c}\text { Number of samples } \\
\text { tested }\end{array}$ & $\begin{array}{l}\text { DTBIA positive ratio } \\
(\%)\end{array}$ & $\begin{array}{c}\text { qPCR positive ratio } \\
(\%)\end{array}$ \\
\hline $\mathrm{B} 232$ & Thailand & CLas & Sweet orange & 30 & 100 & 100 \\
\hline B239 & Taiwan & CLas & Rough lemon & 15 & 98 & 98 \\
\hline B427 & Brazil & CLas & Rough lemon & 15 & 100 & 100 \\
\hline B428 & Florida, U.S.A. & CLas & Rough lemon & 18 & 98 & 98 \\
\hline B429 & Florida, U.S.A. & CLas & Sweet orange & 15 & 100 & 100 \\
\hline B430 & Japan & CLas & Rough lemon & 15 & 97 & 97 \\
\hline B431 & Stellenbosch, South Africa & CLaf & Rough lemon & 15 & 80 & 87 \\
\hline B432 & Nelspruit, South Africa & CLaf & Rough lemon & 15 & 83 & 87 \\
\hline B434 & Nelspruit, South Africa & CLaf & Rough lemon & 15 & 82 & 87 \\
\hline B435 & Letaba, South Africa & CLaf & Rough lemon & 15 & 85 & 86 \\
\hline B436 & Florida, U.S.A. & CLas & Sweet orange & 15 & 100 & 100 \\
\hline B437 & Florida, U.S.A. & CLas & Sweet orange & 15 & 100 & 100 \\
\hline B438 & California, U.S.A. & CLas & Rough lemon & 15 & 80 & 85 \\
\hline B439 & Texas, U.S.A. & CLas & Sweet orange & 15 & 80 & 86 \\
\hline B440 & Pakistan & CLas & Rough lemon & 15 & 82 & 85 \\
\hline Pakn & Pakistan & CLas & Mandarin (Kinnow) & 30 & 100 & 100 \\
\hline VIET & Vietnam & CLas & Rough lemon & 15 & 100 & 100 \\
\hline SA & Saudi Arabia & CLas & Rough lemon & 15 & 100 & 100 \\
\hline JX-QC & China & CLas & Sweet orange & 30 & 100 & 100 \\
\hline YN-NM & China & CLas & Rough lemon & 30 & 98 & 98 \\
\hline YN-ZG & China & CLas & Mandarin (Zagan) & 30 & 100 & 100 \\
\hline FJ-YC & China & CLas & Mandarin (Lvgan) & 30 & 100 & 100 \\
\hline HuN-YZ & China & CLas & Sweet orange & 18 & 100 & 100 \\
\hline GX-STJ & China & CLas & Mandarin (Shatangjv) & 30 & 100 & 100 \\
\hline GX-HP & China & CLas & Sweet orange & 60 & 100 & 100 \\
\hline GD-NJ & China & CLas & Mandarin (Nianjv) & 30 & 100 & 100 \\
\hline $\mathrm{HaN}-\mathrm{LC}$ & China & CLas & Sweet orange & 30 & 100 & 100 \\
\hline $\mathrm{ZJ}-\mathrm{ZG}$ & China & CLas & Mandarin (Aiyuan) & 30 & 100 & 100 \\
\hline
\end{tabular}

${ }^{\text {a }}$ Note: Leaf samples were collected from three individual trees. DTBIA = direct tissue blot immunoassay; qPCR = quantitative PCR; HLB = huanglongbing; CLas $=$ 'Candidatus Liberibacter asiaticus'; and CLaf $=$ 'Ca . L. africanus'. 
rootstock to confirm our protocol is useful for identification of CLas and CLaf, respectively. In petioles, purple reactions were seen only in the phloem (Fig. 2). These results were similar when sweet orange samples were tested (Fig. 2) without preblocking of the anti-Omp Pab. Blocking of the antiserum with 5\% RLCE produced a very clear tissue print without any nonspecific background coloration in the healthy control (Fig. 2). Similar results were observed when midribs and stem sections were tested for CLas and CLaf in the same way (not shown).

We tested a total of 621 tissue prints from 84 trees from different geographic areas (Table 1). For CLas- and CLaf-infected samples, purple color was found only in the phloem. The antiserum recognized CLas bacteria from Thailand, China, Taiwan, Brazil, the United States (Florida, California, and Texas), Japan, Pakistan, and Vietnam. The antiserum also recognized CLaf isolates collected from Stellenbosch, Nelspruit, and Letaba in South Africa. No color was produced in the healthy control samples (Table 1; Fig. 3). CLasinfected samples from eight main citrus-producing provinces in China, including Jiangxi, Yunnan, Fujian, Hunan, Guangxi, Guangdong, Hainan, and Zhejiang, were also collected and tested with the antiOmp Pab. Typical purple color was specifically produced in phloem tissue of prints made from midribs of all samples. For each strain of CLas or CLaf tested, the number of tissue prints evaluated ranged from 15 to 60 (Table 1). The proportion of tissue prints that were clearly positive by the DTBIA was recorded. After the tissue prints were made, DNA was extracted from the 2-mm sections of tissue used to make the tissue prints and assayed by qPCR (Fu et al. 2019b). The overall CLas detection rate by DTBIA was $95.7 \%$, as compared with $96.6 \%$ by qPCR (Table 1 ).

PCR amplicons encoding a portion of the Omp gene were produced, cloned, and sequenced. Analysis of Omp protein sequence data indicated that CLas strains shared 99.2 to $100 \%$ identity, whereas CLaf strains shared 99.6 to $100 \%$ identity. The identity between the CLas and CLaf strains was only 53.8 to $55.9 \%$ at the amino acid level. Phylogenetic analysis based on the partial amino acid sequences of the Omp proteins resolved five clades with bootstrap (1,000 replicates) values $>60$ (not shown). CLaf strains from Stellenbosch, Nelspruit, and Letaba were in a well-separated clade. The predicted three-dimensional structure of Omp proteins of CLas, CLaf, and CLam also showed clear structural similarities and antigenic determinants (not shown).

Although PCR- and qPCR-based methods for detection of CLas are effective, there are inherent limitations to the technology. The

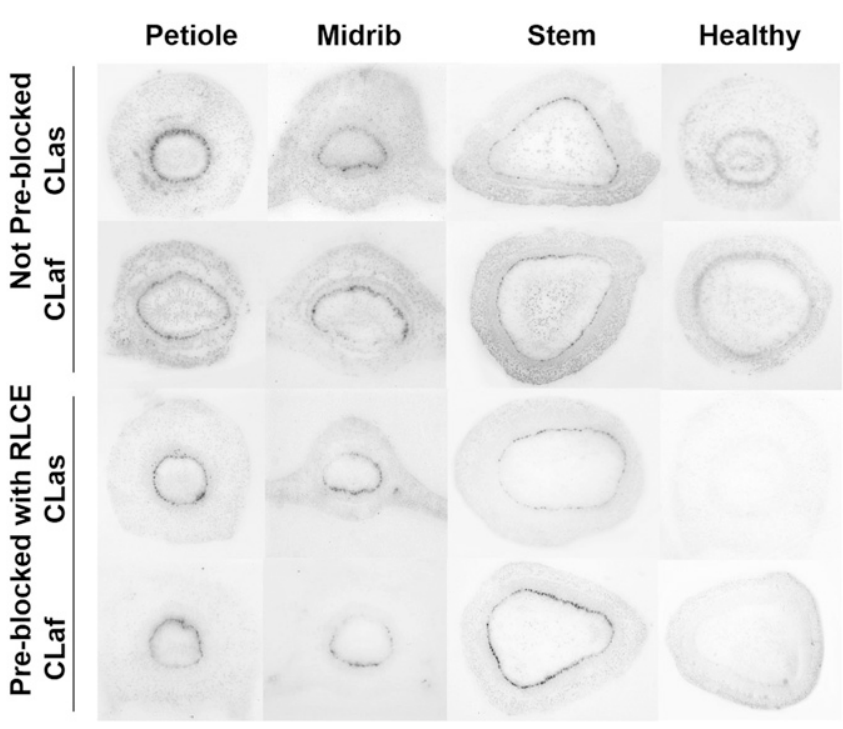

Fig. 1. Comparison of preblocked and unblocked antibodies against 'Candidatus Liberibacter asiaticus' (CLas) and 'Ca. L. africanus' (CLaf) in lemon samples in the direct tissue blot immunoassay. The primary anti-Omp polyclonal antibody was at 5,000 -fold dilution, and the secondary goat antirabbit monoclonal antibody conjugated with alkaline phosphatase was at 50,000-fold dilution. Sections of petioles, midribs, and stems were tested as indicated. Sections of petioles and stems were taken from healthy trees for comparison. RLCE = rough lemon crude extracts. most important is the sheer number of samples that must be taken for testing due to the low concentration and erratic distribution of the pathogen. Concentrations of the pathogen are greater in symptomatic tissue, which is preferred for PCR-based testing, so PCR-based testing is often used for confirmation of HLB initially suspected based on symptoms. There is also a very long latent period between inoculation of a citrus tree with CLas by a psyllid and the expression of symptoms. During this time psyllids reacquire the pathogen and spread the pathogen to other trees. Citrus groves can be very large, and individual trees are difficult to assess visually. For these reasons, a great deal of research is directed to remote sensing or whole-tree-based technologies for early detection of HLB symptoms. These include visible and near-infrared spectroscopy from aerial platforms (Garcia-Ruiz et al. 2013; Sankaran et al. 2011), hyperspectral reflectance (Weng et al. 2018), fluorescence imaging spectroscopy (Wetterich et al. 2016), and survey of citrus groves with trained canines for olfactory detection of CLas (Gottwald et al. 2017).

DTBIA has been widely applied previously to detect pathogens in citrus, including citrus tristeza virus detected with a monoclonal antibody (Garnsey et al. 1993) and CLas detected by PCR using DNA eluted from the tissue print (Bertolini et al. 2014). DTBIA is especially suitable for large-scale screening, for which standard PCR- and qPCR-based assays are slow and expensive primarily due to the necessity for DNA extraction from phloem tissues followed by qPCR reagent and consumable costs. The cost of reagents and consumables needed for the qPCR assay therefore scales linearly with the number of samples tested. Because no sample preparation is needed, and an unlimited number of petioles or midribs can be sampled in the field, DTBIA may be an ideal methodology to use in the validation these novel whole-tree-based HLB diagnostic technologies when foliar symptoms are not present to direct sampling for PCR-based methods. We have shown that DTBIA can detect CLas in asymptomatic foliar and stem tissues (Ding et al. 2017; Fu et al. 2019a). Another serologically based technology that uses a Pab against SDE1, an effector protein secreted by CLas and which may have more systemic distribution than CLas itself, could also be useful for diagnosis of HLB (Pagliaccia et al. 2017). We have shown that the DTBIA is effective in both leaf and root samples (Ding et al. 2015). Testing of root samples may be especially important for early diagnosis of HLB because the pathogen is present in and damaging to citrus roots before foliar symptoms of HLB are observed (Graham et al. 2013; Johnson et al. 2014). Although essentially unlimited numbers of plant samples can be tested concurrently by DTBIA at no additional reagent cost, a significant

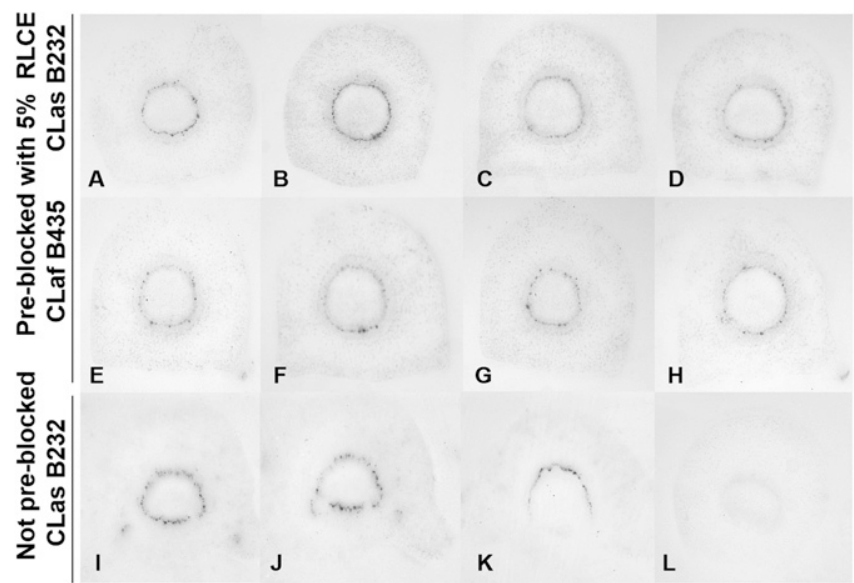

Fig. 2. Detection of both 'Candidatus Liberibacter asiaticus' (CLas) and 'Ca. L. africanus' (CLaf) in citrus petioles with anti-Omp polyclonal antibodies (Pab). Direct tissue blot immunoassay details were as in Figure 1. CLas stain B232 (A to D, I to K) and CLaf strain B435 (E to $\mathbf{H}$ ) were tested in rough lemon sections. Direct tissue blot immunoassay with anti-Omp Pab without preblocking for the detection of CLas was used as a control. No color was observed in the healthy rough lemon control $(\mathbf{L})$. RLCE $=$ rough lemon crude extracts. 
bottleneck in the process is the requirement for visual assessment to declare samples positive or negative. The evaluation of large numbers of tissue print samples without observer bias will be facilitated by the use of an automated detection application developed with the application of machine learning technologies for this purpose (Shao et al. 2020).

The origin of CLas, and therefore its center of diversity, is thought to be Indochina or China. CLas in Brazil, Florida, and elsewhere originate from that region. The diversity of CLas has been studied in Guangdong (Zheng et al. 2018) province and also across all of China, where independent lineages of CLas were identified in highand low-altitude regions (Fu et al. 2020). Our samples tested by DTBIA in this study included the diversity demonstrated for China. We also used DTBIA to test many HLB samples from Japan, Thailand, Vietnam, Pakistan, Saudi Arabia, Brazil, and the United States. The anti-Omp antibody recognized all CLas strains and produced strong purple signals in the phloem. qPCR was also applied to these samples, and the results were strongly correlated (Table 1). The origin of CLaf is in South Africa, and significant diversity of CLaf has been documented within Rutaceae hosts (Roberts and Pietersen 2017; Roberts et al. 2015, 2017). We have demonstrated that the DTBIA with an antibody based on the CLas Omp is effective for detection of CLaf strains isolated from citrus across South Africa (Table 1).

Amino acid sequence data showed homology within CLas and CLaf, with 53.8 to $55.9 \%$ identity at the amino acid level. Structural and antigenic analysis of the Omp proteins of CLas, CLaf, and
CLam showed that they shared similar three-dimensional structure and antigenic determinants, consistent with the similar antigenic determinants (not shown). This explained why the anti-Omp antibodies recognized both CLas and CLaf strains. The outer membrane protein targeted by the antibodies from CLas and ' $\mathrm{Ca}$. L. solanacearum' (CLso) share 59.1\% amino acid identities, higher than the identity between CLas and CLaf (53.8 to 55.9\%), and share epitopes as well. Because the anti-Omp antibodies successfully recognized CLaf in the present study, the antibody would likely also recognize CLso. This needs to be confirmed. The amino acid identity between CLas and CLam is $48.4 \%$, which is lower than that between CLas and CLaf. The anti-Omp antibodies would very likely be effective against CLam, but samples are not available for testing. Meanwhile, the interactions between host plants, psyllids, and liberibacters will be fruitful areas in future research with antibodybased methods.

In conclusion, we have established a rapid and simple serologically based detection method for both CLas and CLaf. The accuracy, simplicity, broad specificity, and low cost will make it an attractive and reliable method for detection of either CLas or CLaf. The assay is a very useful complement to current PCR-based methods.

\section{Author Contributions}

F. Ding designed and initiated the study. S.-A. Peng contributed to the sample collection. J. S. Hartung and F. Ding wrote the manuscript together. All authors gave final approval for publication.

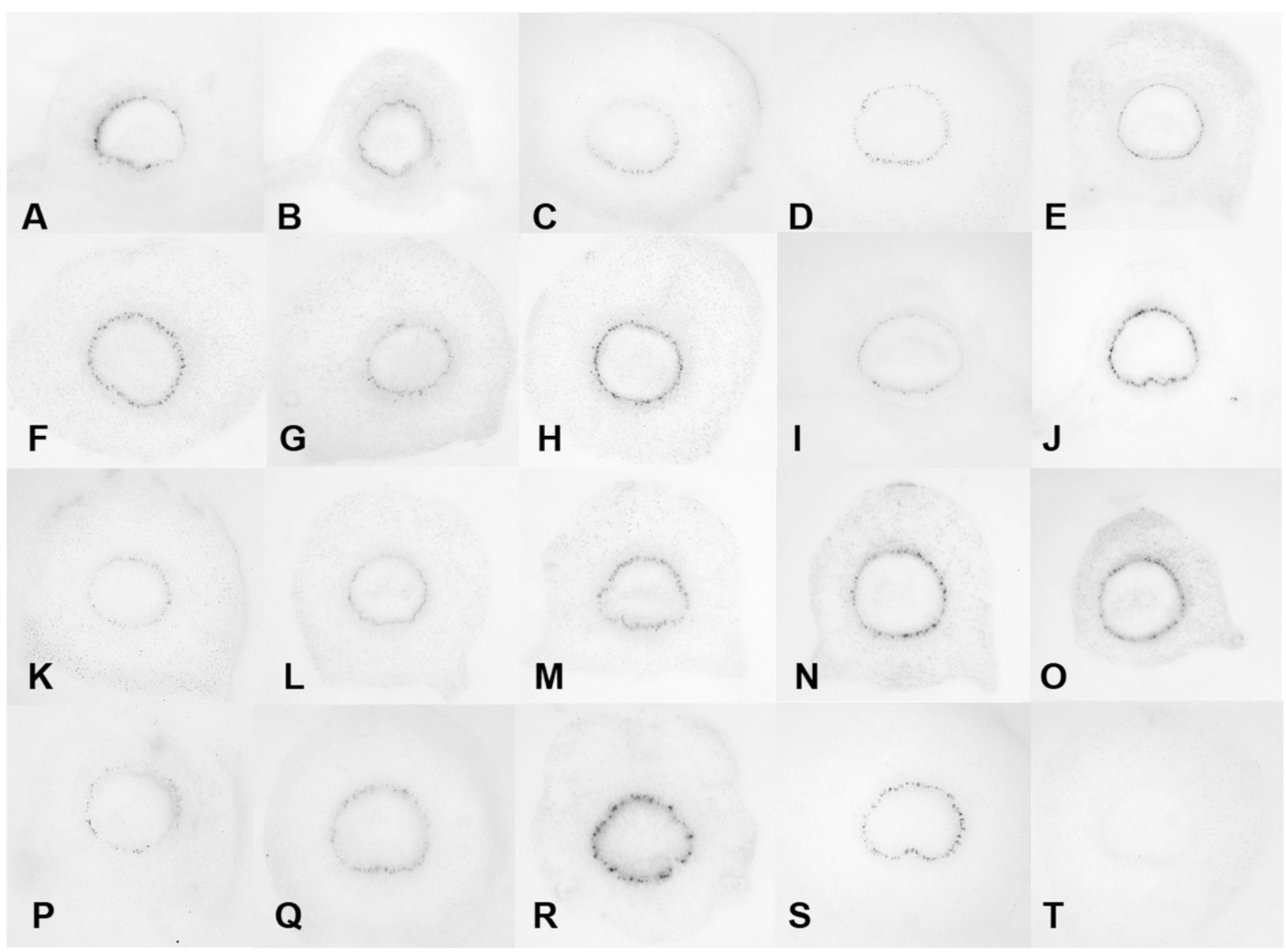

Fig. 3. Detection of 'Candidatus Liberibacter asiaticus' (CLas) and 'Ca. L. africanus' (CLaf) with direct tissue blot immunoassay (DTBIA) in samples that originated in different geographic areas. DTBIA details were as in Figure 1. Samples originated in countries or regions as indicated. Samples from Thailand (A), Taiwan (B), Brazil (C), Japan (D), Florida, U.S.A. (E and F), Texas, U.S.A. (G), California, U.S.A. (H and I), Pakistan (J and K), Saudi Arabia (L), and Vietnam (M) were CLas. Samples from Letaba (N and $\mathbf{0})$, Stellenbosch (P and $\mathbf{Q})$, and Nelspruit (R and $\mathbf{S})$ in South Africa were CLaf. The signals were all located in the phloem. No color was observed in the healthy control (T). 


\section{Literature Cited}

Arredondo Valdés, R., Delgado Ortiz, J. C., Beltrán Beache, M., Anguiano Cabello, J., Cerna Chávez, E., Rodríguez Pagaza, Y., and Ochoa Fuentes, Y. M. 2016. A review of techniques for detecting Huanglongbing (greening) in citrus. Can. J. Microbiol. 62:803-811.

Ayres, A. J., Belasque, J., Jr., and Bové, J. M. 2012. The experience with huanglongbing management in Brazil. Acta Hort. 1065:55-61.

Bertolini, E., Felipe, R. T. A., Sauer, A. V., Lopes, S. A., Arilla, A., Vidal, E., Mourão Filho, F. A. A., Nunes, W. M. C., Bové, J. M., López, M. M., and Cambra, M. 2014. Tissue-print and squash real-time PCR for direct detection of 'Candidatus Liberibacter' species in citrus plants and psyllid vectors. Plant Pathol. 63:1149-1158.

Bové, J. M. 2006. Huanglongbing: A destructive, newly-emerging, century-old disease of citrus. J. Plant Pathol. 88:7-37.

Capoor, S. P., Rao, D. G., and Viswanath, S. M. 1967. Diaphorina citri Kuway., a vector of the greening disease of citrus in India. Indian J. Agric. Sci. 37:572-576.

Cen, Y., Zhang, L., Xia, Y., Guo, J., Deng, X., Zhou, W., Sequeira, R., Gao, J., Wang, Z., Yue, J., and Gao, Y. 2012. Detection of 'Candidatus Liberibacter asiaticus' in Cacopsylla (Psylla) citrisuga (Hemiptera: Psyllidae). Fla. Entomol. 95:304-311.

Coletta-Filho, H. D., Targon, M. L. P. N., Takita, M. A., Negri, J. D. D., Pompeu, J., and Machado, M. A. 2004. First report of the causal agent of huanglongbing ('Candidatus Liberibacter asiaticus') in Brazil. Plant Dis. 88:1382.

da Graca, J. V. 1991. Citrus greening disease. Annu. Rev. Phytopathol. 29:109-136.

De Boer, S. H., and Lopez, M. M. 2012. New grower friendly methods for plantpathogen monitoring. Annu. Rev. Phytopathol. 50:197-218.

Ding, F., Duan, Y., Paul, C., Brlansky, R. H., and Hartung, J. S. 2015. Localization and distribution of 'Candidatus Liberibacter asiaticus' in citrus and periwinkle by direct tissue blot immuno assay with an anti-OmpA polyclonal antibody. PLoS One 10:e0123939.

Ding, F., Duan, Y., Yuan, Q., Shao, J., and Hartung, J. S. 2016. Serological detection of 'Candidatus Liberibacter asiaticus' in citrus, and identification by GeLC-MS/ MS of a chaperone protein responding to cellular pathogens. Sci. Rep. 6:29272.

Ding, F., Paul, C., Brlansky, R., and Hartung, J. S. 2017. Immune tissue print and immune capture-PCR for diagnosis and detection of Candidatus Liberibacter asiaticus. Sci. Rep. 7:46467.

Duan, Y., Zhou, L., Hall, D. G., Li, W., Doddapaneni, H., Lin, H., Liu, L., Vahling, C. M., Gabriel, D. W., Williams, K. P., Dickerman, A., Sun, Y., and Gottwald, T. 2009. Complete genome sequence of citrus huanglongbing bacterium, 'Candidatus Liberibacter asiaticus' obtained through metagenomics. Mol. Plant-Microbe Interact. 22:1011-1020.

Fu, S., Bai, Z., Su, H., Liu, J., Hartung, J. S., Zhou, C., and Wang, X. 2020. Occurrence of prophage and historical perspectives associated with the dissemination of huanglongbing in mainland China. Plant Pathol. 69:132-138.

Fu, S., Gouin, C., Zhou, C.-y., and Hartung, J. S. 2019a. Limited infection by 'Candidatus Liberibacter asiaticus' in 'Valencia' sweet orange trees in the presence of Citrus tristeza virus. J. Integr. Agric. 18:2284-2293.

Fu, S. M., Liu, H. W., Liu, Q. H., Zhou, C. Y., and Hartung, J. S. 2019b. Detection of 'Candidatus Liberibacter asiaticus' in citrus by concurrent tissue print-based qPCR and immunoassay. Plant Pathol. 68:796-803.

Garcia-Ruiz, F., Sankaran, S., Maja, J. M., Lee, W. S., Rasmussen, J., and Ehsani, R. 2013. Comparison of two aerial imaging platforms for identification of huanglongbing-infected citrus trees. Comput. Electron. Agric. 91:106-115.

Garnier, M., Bové, J., Danel, N., and Bove, J. M. 1984. The greening organism is a gram negative bacterium. 9th Conference of the International Organization of Citrus Virologists, Iguacu, Argentina.

Garnsey, S. M., Permar, T. A., Cambra, M., and Henderson, C. T. 1993. Direct tissue blot immunoassay (DTBIA) for detection of citrus tristeza virus (CTV). 12th Conference of the International Organization of Citrus Virologists.

Gottwald, T. R. 2010. Current epidemiological understanding of citrus huanglongbing. Annu. Rev. Phytopathol. 48:119-139.

Gottwald, T. R. and McCollum, T. G. 2017. Huanglongbing solutions and the need for anti-conventional thought. J. Citrus Pathol. 4:36952.

Gottwald, T. R., Poole, G. H., Taylor, E. L., Hartung, J. S., Hall, D. G., Bartels, D., McCollum, T. G., Hilf, M. E., Luo, W., Louws, F., Polek, M., Vidalakis, G., and Mauk, P. 2017. Use of HLB detection canines in real world settings. J. Citrus Pathol. 4:16-45.

Graham, J. H., Johnson, E. G., Gottwald, T. R., and Irey, M. S. 2013. Presymptomatic fibrous root decline in citrus trees caused by huanglongbing and potential interaction with Phytophthora spp. Plant Dis. 97:1195-1199.

Halbert, S. E. 2005. The discovery of huanglongbing in Florida. Proceedings of 2nd International Citrus Canker and Huanglongbing Research Workshop. Florida Citrus Mutual, Orlando, FL.

Hocquellet, A., Toorawa, P., Bové, J. M., and Garnier, M. 1999. Detection and identification of the two Candidatus Liberobacter species associated with citrus huanglongbing by PCR amplification of ribosomal protein genes of the $\beta$ operon. Mol. Cell. Probes 13:373-379.

Jagoueix, S., Bove, J. M., and Garnier, M. 1994. The phloem-limited bacterium of greening disease of citrus is a member of the alpha subdivision of the Proteobacteria. Int. J. Syst. Bacteriol. 44:379-386.

Johnson, E. G., Wu, J., Bright, D. B., and Graham, J. H. 2014. Association of 'Candidatus Liberibacter asiaticus' root infection, but not phloem plugging with root loss on huanglongbing-affected trees prior to appearance of foliar symptoms. Plant Pathol. 63:290-298.
Korsten, L. G., Sanders, G. M., Su, H. J., Bové, J. M., and Kotze, J. M. 1993 Detection of citrus greening infected citrus in South Africa using a DNA probe and monoclonal antibodies. Pages 224-234 in: Proceedings of the 12th Conference of the International Organization of Citrus Virologists. P Moreno, J. V. da Graça, and L. W.Timmer, eds. IOCV, Riverside CA.

Li, W., Hartung, J. S., and Levy, L. E. 2006. Quantitative real time PCR for detection and identification of Candidatus Liberibacter species associated with citrus huanglongbing. J. Microbiol. Methods 66:104-115.

Li, W., Levy, L., and Hartung, J. S. 2009. Quantitative distribution of 'Candidatus Liberibacter asiaticus' in citrus plants with citrus huanglongbing. Phytopathology 99:139-144.

Li, W. B., Li, D. Y., Twieg, E., Hartung, J. S., and Levy, L. 2008. Optimized quantification of unculturable Candidatus Liberibacter spp. in host plants using real-time PCR. Plant Dis. 92:854-861.

Lin, H., Pietersen, G., Han, C., Read, D. A., Lou, B., Gupta, G., and Civerolo, E. L. 2015. Complete genome sequence of "Candidatus Liberibacter africanus," a bacterium associated with citrus huanglongbing. Genome Announc. 3: e00733-15.

Lin, N. S., Hsu, H. Y., and Hsu, H. T. 1990. Immunological detection of plant viruses and mycoplasmalike organism by direct tissue blotting on nitrocellulose membranes. Phytopathology 80:824-828.

Martinez, A., and Wallace, J. 1967. Citrus leaf mottle-yellows disease in the Philippines and transmission of the causal virus by a psyllid, Diaphorina citri. Plant Dis. Rep. 51:692-695.

Okuda, M., Matsumoto, M., Tanaka, Y., Subandiyah, S., and Iwanami, T. 2005. Characterization of the tufB-secE-nusG-rplKAJL-rpoB gene cluster of the citrus greening organism and detection by loop-mediated isothermal amplification. Plant Dis. 89:705-711.

Pagliaccia, D., Shi, J., Pang, Z., Hawara, E., Clark, K., Thapa, S. P., De Francesco, A., Liu, J., Tran, T.-T., Bodaghi, S., Folimonova, S. Y., Ancona, V. Mulchandani, A., Coaker, G., Wang, N., Vidalakis, G., and Ma, W. 2017. A pathogen secreted protein as a detection marker for citrus huanglongbing. Front. Microbiol. 8:2041.

Pietersen, G., Arrebola, S. A. E., Korsten, L., le Roux, H. F., la Grange, H., Lopes, S. A., Meyer, J. B., Pretorius, M. C., Schwerdtfeger, M., van Vuuren, S. P., and Yamamoto, P. 2010. A survey for 'Candidatus Liberibacter' species in South Africa confirms the presence of only ' $\mathrm{Ca}$. L. africanus' in commercial citrus. Plant Dis. 94:244-249.

Roberts, R., Cook, G., Grout, T. G., Khamis, F., Rwomushana, I., Nderitu, P. W. Seguni, Z., Materu, C. L., Steyn, C., Pietersen, G., Ekesi, S., and le Roux, H. F 2017. Resolution of the identity of 'Candidatus Liberibacter' species from huanglongbing-affected citrus in East Africa. Plant Dis. 101:1481-1488.

Roberts, R., and Pietersen, G. 2017. A novel subspecies of 'Candidatus Liberibacter africanus' found on native Teclea gerrardii (family: Rutaceae) from South Africa. Antonie van Leeuwenhoek 110:437-444.

Roberts, R., Steenkamp, E. T., and Pietersen, G. 2015. Novel lineages of 'Candidatus Liberibacter africanus' associated with native rutaceous hosts of Trioza erytreae in South Africa. Int. J. Syst. Evol. Microbiol. 65:723-731.

Sankaran, S., Mishra, A., Maja, J. M., and Ehsani, R. 2011. Visible-near infrared spectroscopy for detection of huanglongbing in citrus orchards. Comput. Electron. Agric. 77:127-134.

Shao, J., Ding, F., Fu, S., and Hartung, J. S. 2020. Automated detection of ' $\mathrm{Ca}$. Liberibacter asiaticus' infection in citrus using immune tissue prints and machine learning. Plant Diseases and Food Security in the 21st Century. P. R. Scott, R. N. Strange, L. Korsten, and M. L. Gullino, eds. Springer, Dordrecht, the Netherlands.

Tatineni, S., Shankar Sagaram, U., Gowda, S., Robertson, C. J., Dawson, W. O., Iwanami, T., and Wang, N. 2008. In planta distribution of 'Candidatus Liberibacter asiaticus' as revealed by polymerase chain reaction (PCR) and real-time PCR. Phytopathology 98:592-599.

Teixeira, D., Saillard, C., Eveillard, S., Danet, J. L., da Costa, P. I., Ayres, A. J., and Bove, J. M. 2005. 'Candidatus Liberibacter americanus', associated with citrus huanglongbing (greening disease) in Sao Paulo State, Brazil. Int. J. Syst. Evol. Microbiol. 55:1857-1862

Villechanoux, S., Garnier, M., Renaudin, J., and Bové, J. M. 1992. Detection of several strains of the bacterium-like organism of citrus greening disease by DNA probes. Curr. Microbiol. 24:89-95.

Wang, N., and Trivedi, P. 2013. Citrus huanglongbing: A newly relevant disease presents unprecedented challenges. Phytopathology 103:652-665.

Weng, H., Lu, J., Cen, H., He, M., Zeng, Y., Hua, S., Li, H., Meng, Y., Fang, H., and $\mathrm{He}, \mathrm{Y}$. 2018. Hyperspectral reflectance imaging combined with carbohydrate metabolism analysis for diagnosis of citrus huanglongbing in different seasons and cultivars. Sens. Actuators B Chem. 275:50-60.

Wetterich, C. B., Neves, R. F., Belasque, J. J., and Marcassa, L. G. 2016. Detection of citrus canker and huanglongbing using fluorescence imaging spectroscopy and support vector machine technique. Appl. Opt. 55:400-407.

Wulff, N. A., Zhang, S., Setubal, J. C., Almeida, N. F., Martins, E. C., Harakava, R., Kumar, D., Rangel, L. T., Foissac, X., Bove, J. M., and Gabriel, D. W. 2014 The complete genome sequence of 'Candidatus Liberibacter americanus', associated with citrus huanglongbing. Mol. Plant-Microbe Interact. 27: 163-176.

Zheng, Z., Chen, J., and Deng, X. 2018. Historical perspectives, management, and current research of citrus HLB in Guangdong province of China, where the disease has been endemic for over a hundred years. Phytopathology 108:1224-1236. 